\title{
Seepage phenomenon for Wadi Megenin dam
}

\author{
Salaheddin Shmela ${ }^{1}$, Eng. Najy Shakshem ${ }^{2}$ \\ ${ }^{1}$ Tripoli University, Civil Engineering Department, Tripoli, Libya \\ ${ }^{2}$ General water associations, Tripoli, Libya \\ Email address: \\ sshmela@yahoo.com(S. Shmela),ydoydoo@yahoo.com(E. N. Shakshem)
}

\section{To cite this article:}

Salaheddin Shmela, Eng. Najy Shakshem. Seepage Phenomenon for Wadi Megenin Dam. International Journal of Environmental Monitoring and Analysis. Vol. 1, No. 5, 2013, pp. 248-257. doi: 10.11648/j.ijema.20130105.20

\begin{abstract}
Most of the recorded dam failures in different parts of the world were related to seepage problems. Avoiding earth dam's failure due to seepage usually requires evaluating settlement, and piping, through field monitoring. The problem of dam seepage was experienced in The $38 \mathrm{~m}$ high rock fill Megenin dam is a at located at Souk AL khamis area $75 \mathrm{Km}$ south of Tripoli. The dam was constructed in 1972, for two main purposes; to provide flood controls of the downstream areas, the cultivated fields and Tripoli city, and also provides water for irrigation purpose . The rock-fill dam was supported with an upstream reinforced concrete membrane on the upstreamface consisted of a number of concrete panels, linked together with central rubber water stops, and surface-sealed with a bituminous sealant. A concrete cut-off wall and grout curtain were constructed below the dam body to prevent reservoir seepage through the foundation. It was observed during the $3^{\text {rd }}$ filling of the reservoir at the reservoir storage water level at $+271.86 \mathrm{~m}$ on $15^{\text {th }}$ May 2003 , seepage occurred at the wadi bed downstream of the main dam. The seepage occurred at a piezometric water level higher than the previously measurements during the period of 1973 to 1974. Seepage problem was also encountered in previous reservoir operation. To assess the seepage phenomena and it's impact on the dam safety, a study was carreied out through appliaction of $t$ ground penetrating radar survey (GPR), piezometric analysis, and temperature field evaluation techniques as well as the construction of a flow net model for the dam. The results of the study showed that: the GPR profiles have delineated the critical zones in the dam body, identify the water seepage paths from the reservoir to the down stream side of the dam, estimated the seepage rate through the dam foundation as 0.08 Lliter/ssecond and suggested measures to avoid problem that may occur in the future in Megenin dam due to seepage problems The study revealed the needs to design and implement effective monitoring program ,establish surface water gauging for any sudden increase in the seepage discharge in bed wadi at downstream, groundwater water levels fluctuation in the observation and seepage water beyond the dam. Maintain the upstream concrete facing joints and in case of alert condition occurred undertake additional raw of grouting curtain along the full length of the dam to protect dam foundation from flow.
\end{abstract}

Keywords: Seepage, GPR, Dam, Megenin

\section{Introduction}

Wadi Megenin Dam is located in Souk AL khamis area, $75 \mathrm{Km}$ south of Tripoli city as shown in figure(1). The dam was constructed in 1972, for two main purposes; to provide flood control for the downstream cultivated fields, City of Tripoli and also provide water for irrigation. The dam is $38 \mathrm{~m}$ high, $800 \mathrm{~m}$ long at the crest, and the reservoir capacity is $58 \mathrm{Mm}^{3}$.In order to strengthen water retention in the reservoir, two subsidiary dams were constructed, of which one is a rock-fill dam the other is concrete.

The dam is a rock-fill with an upstream reinforced concrete membrane on the upstreamface and consists of a number of concrete panels, linked together with central rubber water stops, and surface-sealed with a bituminous sealant (GWA, 2007) as shown in figures (2 and 3). A line of cylindrical concrete piles of approximately $19 \mathrm{~m}$ depth, with a cement grout curtain injected below the piles which across the alluvial floor of the valley and connect with the limestone rock below. A short section of conventional reinforced concrete wall, extending to shallower depths, has formed at each end of the line of piles. There are 22 piezometers located in and around the dam to monitor water movement under and through the dam. 


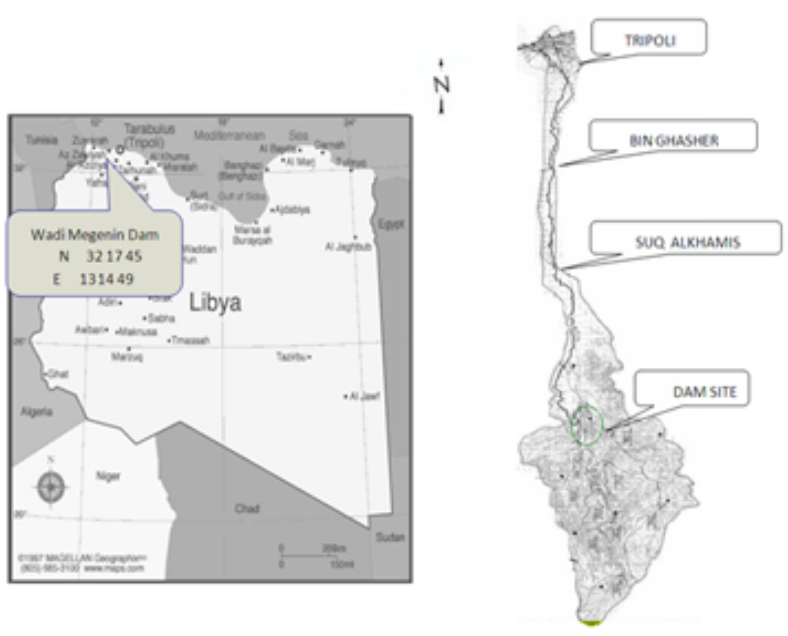

Figure (1): Location map for Megenin dam

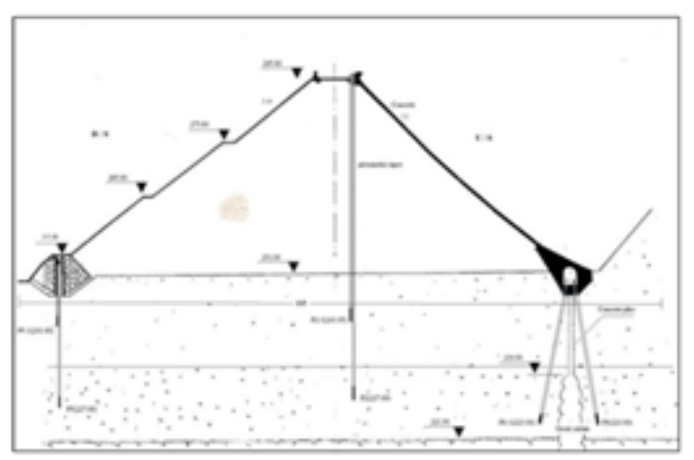

Figure (3): Cross section of Megenin dam

Seepage was observed in the wadi bed downstream of the dam shortly after its completion. Following the rainfall event of $29^{\text {th }}$ of September 1979, the visual inspection made on $27^{\text {th }}$ October 1979 revealed seepage water in the wadi bed downstream of main dam as shown in figure (4). The Piezometric water level was much higher compared to that measured during the period of 1973 to 1974 . The amount of seepage was gradually decreased to a negligibl amount by the end of December due to the lowering of the water level. The water lost during the period from $1^{\text {st }}$ of November 1979 to $31^{\text {th }}$ of December 1979 was estimated at 4.257 million $\mathrm{m}^{3}$ ( $\left.\mathrm{mcm}\right)$.

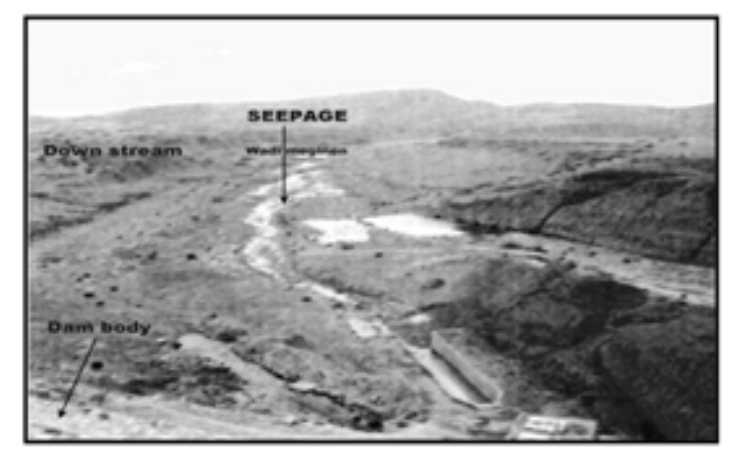

Figure (4): seepage phenomenon downstream of the dam

The major part of this loss is expected to be caused by seepage through the surrounding area.. Another observation was noticed, at the right bank adjacent to the spillway channel and in the wadi at the dam downstream side, on the $15^{\text {th }}$ of May 2003 when the water level in the reservoir reached $271.86 \mathrm{~m}$ (figure 4).To Evaluate the seepage problem in Wadi Megenin dam, seepage data recorded in dam site was analyzed and also assess the impact of seepage phenomena on the dam foundation

\section{Methods}

Seepage in wadi Megenin was evaluated by different methods. The field evaluation was implemented using GPR profiling, groundwater and temperature level information. The field survey has focused on evaluating the existence of critical zones in dam body, water seepage paths through dam foundation and surrounding area, also to determine the geometry of weather zones The analyses focused on determining the direction of seepage flow using the ground penetrating radar (GPR), whereas the amount and behavior of seepage were evaluated using Piezometric level, flow net and temperature field evaluation. The methodology main components consisted of;

\section{i- Ground Penetrating Radar (GPR)}

Geophysical techniques have been applied for monitoring and investigating of piping or erosion in foundation and through dams. One of these methods is using the GPR which is considered to be a very effective tool in ground investigations, normally from the near surface to a depth of several meters. The GPR equipment can easily move on the ground surface and is suitable for survey of vast areas.

GPR can map subsurface structure depths from a few centimeters to five meters. However, GPR is a subsurface imaging can provide high resolution information to a depth of typically $0-40 \mathrm{~m}$. The detectable range of GPR survey depends on soil and sediment mineralogy, clay content, but the most important factor is the water content in the soil. Internal erosion affects the porosity of material in the soil and increases the water content. Also electromagnetic wave can easily penetrate into dry soil; therefore, GPR can easily be applied in our case

The GPR methodology is similar to that of normal radars as an electromagnetic signal (EM) formed by a wave train of selected frequencies is sent by a transmitting antenna and processed to obtain an image of the target. Radar investigations are suitable for other materials, beside subsoil, such as concrete, rock and asphalt. The only difference between common radars and GPR radar is that the GPR antenna sends its signals into the subsoil or into other media that differ from the air in term of homogeneity, electromagnetic parameters and attenuation. Radar measurements can detect these changes since they influence the radio wave velocity.

The transmitted electromagnetic energy is reflected from various buried objects or distinct contacts between different 
earth materials, across which there is a contrast in dielectric constant. The antenna then receives the reflected waves and displays them in time on screen. In the air an electromagnetic signal travels at a velocity of about $30 \mathrm{~cm}$ per nanoseconds $\left(1 \mathrm{~ns}=1 \times 10^{-9} \mathrm{~s}\right)$. Data is saved in appropriate memory for later processing.

A typical GPR system shown in figure (5) has three main components: transmitter (TX) and receiver (RX) that are directly connected to an antenna and a control unit (CU).

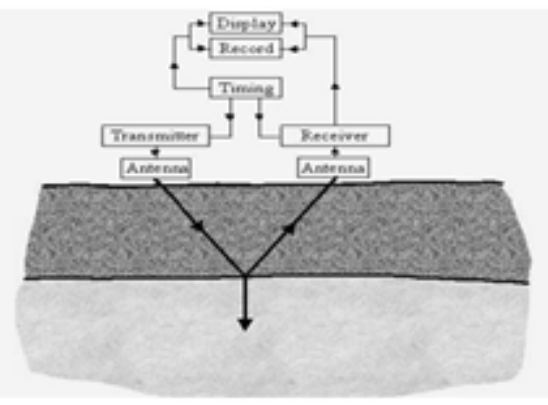

Figure (5): Flow chart for a typical GPR system

Surveis were carried out in April and June, 2007 by the tools as shown in figure (6). The dam reservoir was dry with bed surface elevation of $263 \mathrm{~m}$ (a.s.l), used for surveying different TWT (Recording two-way time) of 1000 nanoseconds. Twelve profiles were made mostly parallel to the dam axis, and run on the bed of the reservoir as shown in figure (7) and table (1).

Three of the selected profiles $\left(\operatorname{Pr}_{10}, \operatorname{Pr}_{11}\right.$, and $\left.\operatorname{Pr}_{12}\right)$ were surveyed downstream.

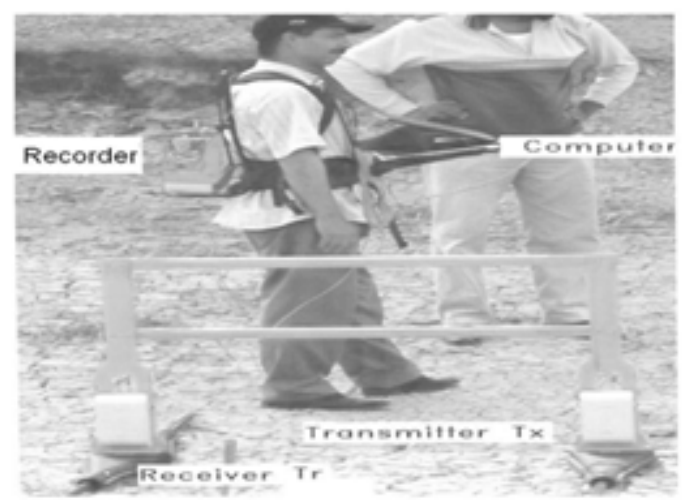

Figure (6): GPR system used in Megenin dam

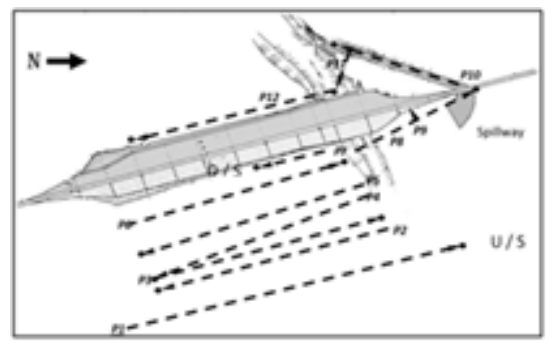

Figure (7): General layout of GRP profiles

Table (1): GRP survey profile coordinates

\begin{tabular}{|c|c|c|c|c|c|}
\hline $\begin{array}{l}\text { Profiles } \\
\text { NO. }\end{array}$ & $\begin{array}{l}\text { Start points } \\
\text { coordinates } \\
\mathrm{X}\end{array}$ & $\mathbf{Y}$ & $\begin{array}{l}\text { End points } \\
\text { coordinates } \\
\text { X }\end{array}$ & $\mathbf{Y}$ & Length (m) \\
\hline $\operatorname{Pr}_{1}$ & 3573947.8 & 335299.9 & 3574793 & 335156.5 & 857 \\
\hline $\operatorname{Pr}_{2}$ & 3574680.8 & 335066.7 & 3574096.9 & 335185 & 596 \\
\hline $\operatorname{Pr}_{3}$ & 3574096.9 & 335185 & 3574680.8 & 335066.7 & 596 \\
\hline $\operatorname{Pr}_{4}$ & 3574656 & 335015.9 & 3574096.9 & 335185 & 584 \\
\hline $\operatorname{Pr}_{5}$ & 3574657.3 & 334976.6 & 3574071.3 & 335111.9 & 601 \\
\hline $\operatorname{Pr}_{6}$ & 3574071.3 & 335111.9 & 3574657.3 & 334976.6 & 601 \\
\hline $\operatorname{Pr}_{7}$ & 3574640.1 & 334940.4 & 3574529 & 334975.6 & 117 \\
\hline $\operatorname{Pr}_{8}$ & 3574653.8 & 334962.5 & 3574799.3 & 334895 & 160 \\
\hline $\operatorname{Pr}_{9}$ & 3574740.52 & 3344077.4 & 3574708.02 & 334113.58 & 49 \\
\hline $\mathrm{pr}_{10}$ & 3574575.3 & 334749.6 & 3574764.8 & 334835.5 & 208 \\
\hline $\mathrm{pr}_{11}$ & 3574618.7 & 334834.3 & 3574660 & 334798.3 & 55 \\
\hline $\operatorname{Pr}_{12}$ & 3574167.4 & 334991.7 & 3574589 & 334860.7 & 441 \\
\hline
\end{tabular}

Note: Coordinates are listed by using GPS system (UTM Zone 35).

Modern GPR processing make the profiles look so much like cross-sections through the earth, that it is tempting to interpret them as such. In some ways, this is a useful way of thinking because it drives the development of acquisition sensors and processing methods forward to this goal.
However, excluding simple and normal cases, GPR sections are not simple slices through the earth. This is mainly because of the nature of propagation and interaction of the EM wave inside and outside the ground, and its sensitivity to reflect interfaces and objects, which are not necessarily the same interfaces and objects that would be visible to the eyes. Yet, a proper interpretation of a GPR 
profile should be based on the comprehensive understanding of geological and environmental conditions.

\section{ii. Piezometric Groundwater Level}

The seepage problem was evaluated using the groundwater level recorded since 1972 by the 22 piezometers that are distributed around the dam surrounding and reservoir lake. The piezometers are arranged in three sections as shown in figure (13).

\section{iii. Ttemperature Evaluation}

The temperature variation in the groundwater observation piezometers at two periods February ,17 and 21,2008 shown in tables (2 and 3) was evaluated .The temperatures indicate the most direct connection with cold water from reservoir.

\section{iv. Flow Net Modeling}

The flow net was constructed using the piezometric levels in combination with topographical counour information. The piezometric groundwater levels measurements recorded on November 11, 2003 was used to plot water level in contour map as the selected date represented the highest recorded reservoir water level at 272.o2 (m a.s.1).

\section{iv. Flow Net Modeling}

The flow net was constructed using the piezometric levels in combination with topographical counour information. The piezometric groundwater levels measurements recorded on November 11, 2003 was used to plot water level in contour map as the selected date represented the highest recorded reservoir water level at 272.02 (m a.s.l).

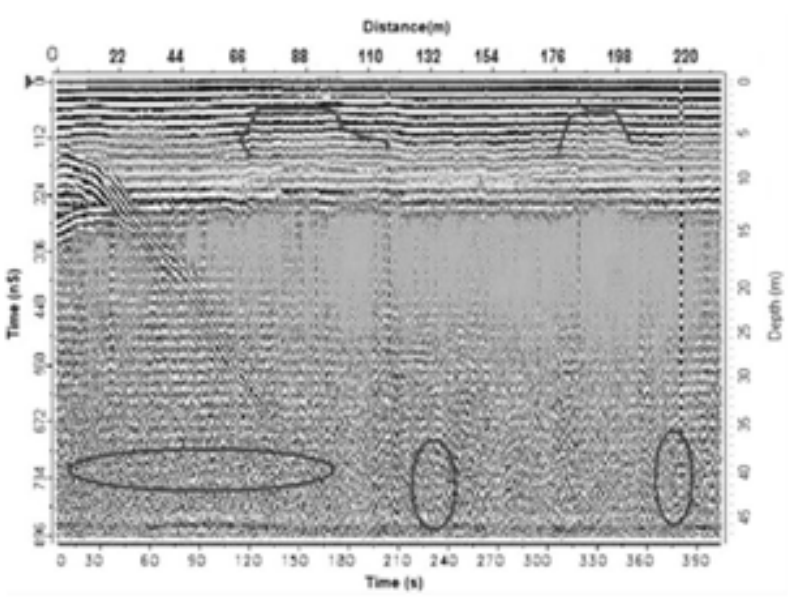

Figure (8a): Profile (Pr $)$ records of EM, using antenna $50 M H Z$

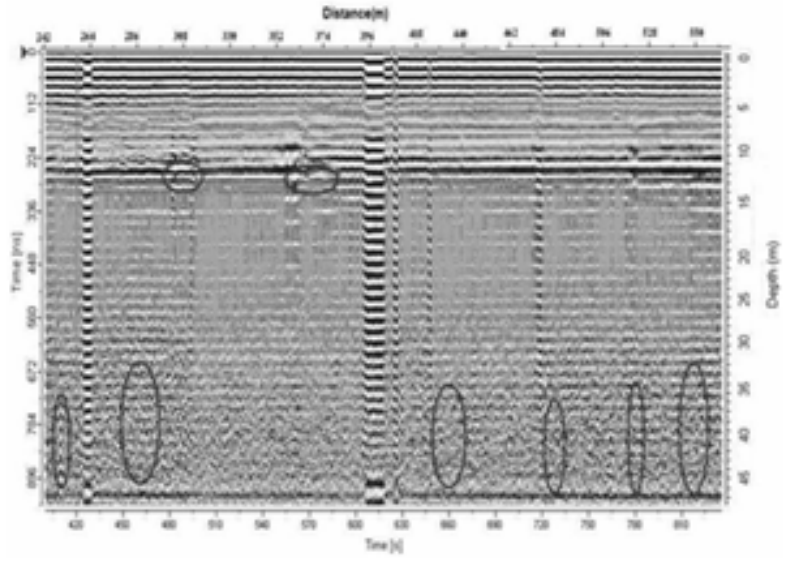

Figure (8b): Profile (Pr $)$ records of EM, using antenna 50MHZ

\section{Distance (m)}

$550 \quad 572594616 \quad 638 \quad 660682704726748770792814836$

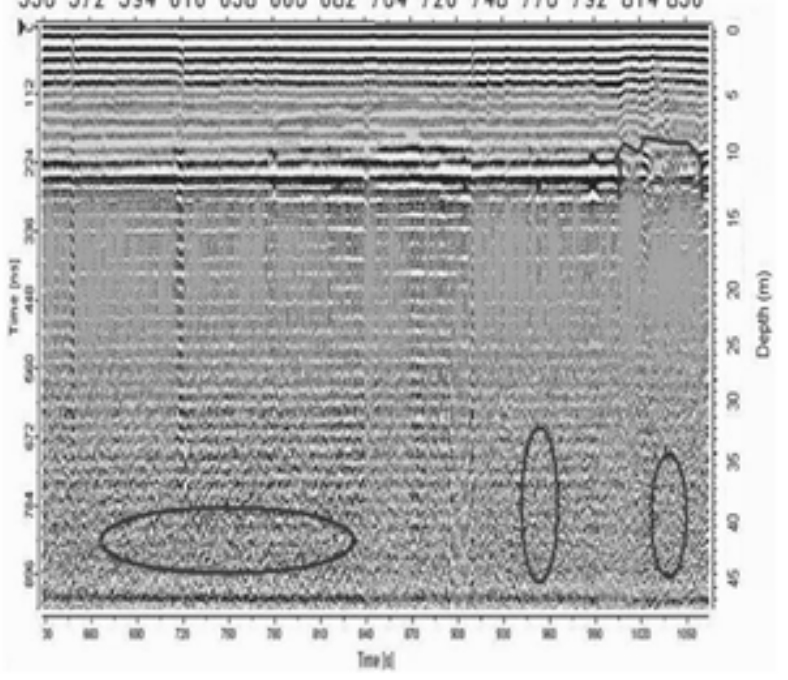

Figure (8c): Profile (Pr $)$ records of EM, using antenna

\section{Analyses}

\section{i. Ground Penetrating Radar (GPR)}

Profiles $\left(\operatorname{Pr}_{1}\right),\left(\operatorname{Pr}_{3}\right),\left(\operatorname{Pr}_{10}\right)$ and $\left(\operatorname{Pr}_{12}\right)$ will be interpolated as follow. Profile $\left(\operatorname{Pr}_{1}\right)$ is located upstream with a length of $857 \mathrm{~m}$, runs parallel to the dam axis as shown in figure (7), starting from the left bank of the reservoir to the right bank.. The profile depth surveyed was $52 \mathrm{~m}$ (at an elevation 211 $\mathrm{m}$ a.s.l) with antenna ranging $(50 \mathrm{MHz})$. The G.P.R profile (image) has showed a series groups of strong reflections along the profile, evidenced by blue dark color shown in figure $(8 \mathrm{a}, \mathrm{b}$, and $\mathrm{c})$. Families of voids determined reflect critical zones developed due to wash out of fine materials. Those critical zones called anomaly objects located at depth $35 \mathrm{~m}$ to $45 \mathrm{~m}$. The forms of these objects are about $(20 \times 10$ $\mathrm{m}^{2}$ to $10 \times 150 \mathrm{~m}^{2}$ ). The strata permeability along these critical zones is expected to increase leads to erosion or piping.

Profile $\left(\mathrm{Pr}_{3}\right)$ is located in the opposite direction of path $\left(\mathrm{Pr}_{2}\right)$ with length of $570 \mathrm{~m}$ shown in figure (9), oriented from (N-S). In this profile antenna $25 \mathrm{MHz}$ was used in the 
survey to check the existence of previous anomalies and increasing the recording depth as this profile located near the dam axis.

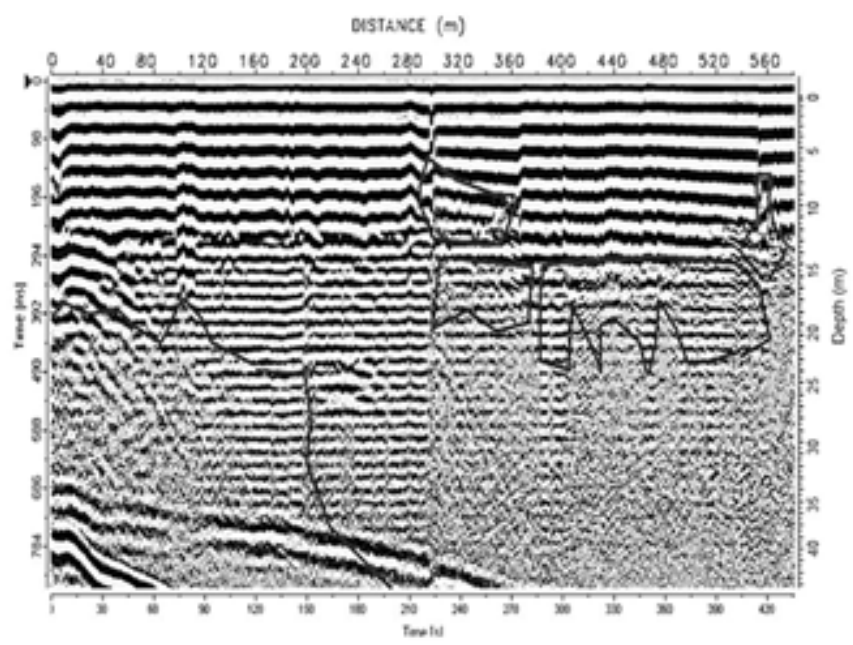

Figure (9): Profile ( $\mathrm{Pr}_{3}$ ) record of EM, using antenna $25 \mathrm{MHz}$

Profile $\left(\operatorname{Pr}_{10}\right)$ is located over the spillway downstream, oriented from the crest to valley bed. Antenna of $50 \mathrm{MHz}$ was used to survey this profile for the sake of better resolution. GPR profile has recorded some parallel anomalies at depth $5 \mathrm{~m}$, beyond $115 \mathrm{~ns}$ and distance from 90 $\mathrm{m}$ to180 $\mathrm{m}$ shown I figure (10).

Profile $\left(\operatorname{Pr}_{12}\right)$ is located near the toe of the dam downstream, with (N-S) direction, and $50 \mathrm{MHz}$ antenna was used. GPR profile shown in figure (11) pointed out anomalie at depth $3 \mathrm{~m}$, beyond $100 \mathrm{~ns}$ depth $5 \mathrm{~m}$ and beyond $118 \mathrm{~ns}$.

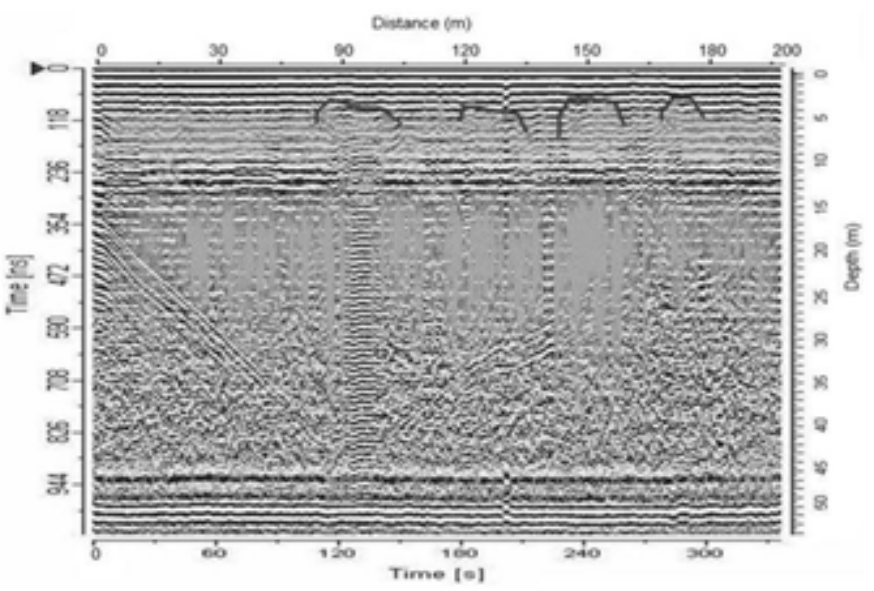

Figure (10): Profile (Pr $\left.{ }_{10}\right)$ records of EM, using antenna $50 \mathrm{MHz}$

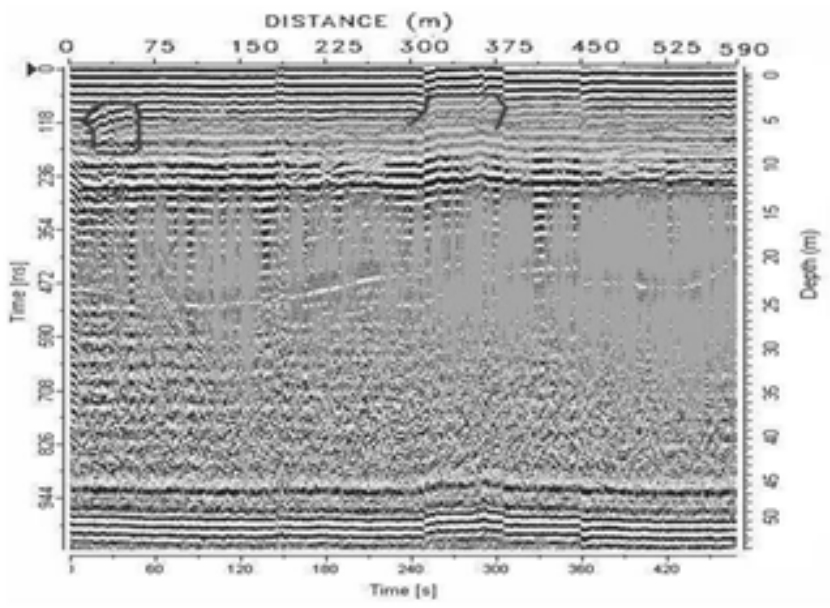

Figure (11): Profile ( $\left.\mathrm{Pr}_{12}\right)$ records of EM, using antenna $50 \mathrm{MHz}$

The piezometers located in the dam gallery are (P7, P7-1, P8, P8-1, P9 and P 9-1) shown in figure (14). The data selected for analysis were chosen for selective five years periods 1980, 1992, 2003, 2004 and 2005 showing maximum reservoir water levels.

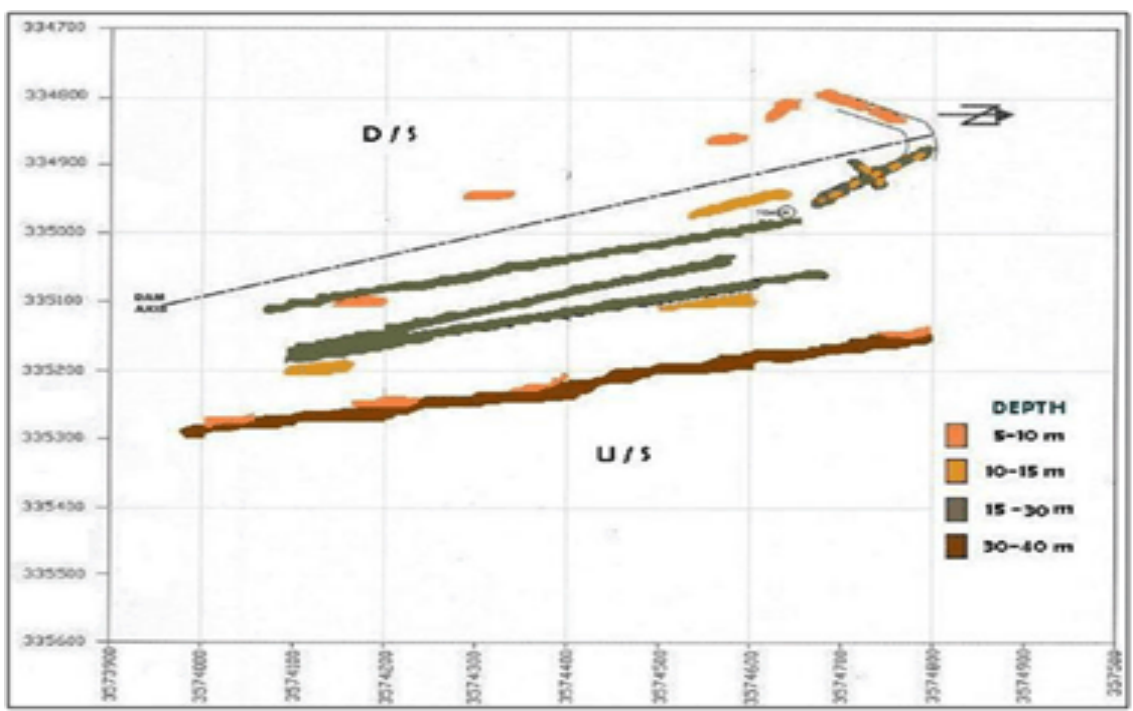

Figure (12): Location of anomalous zone 


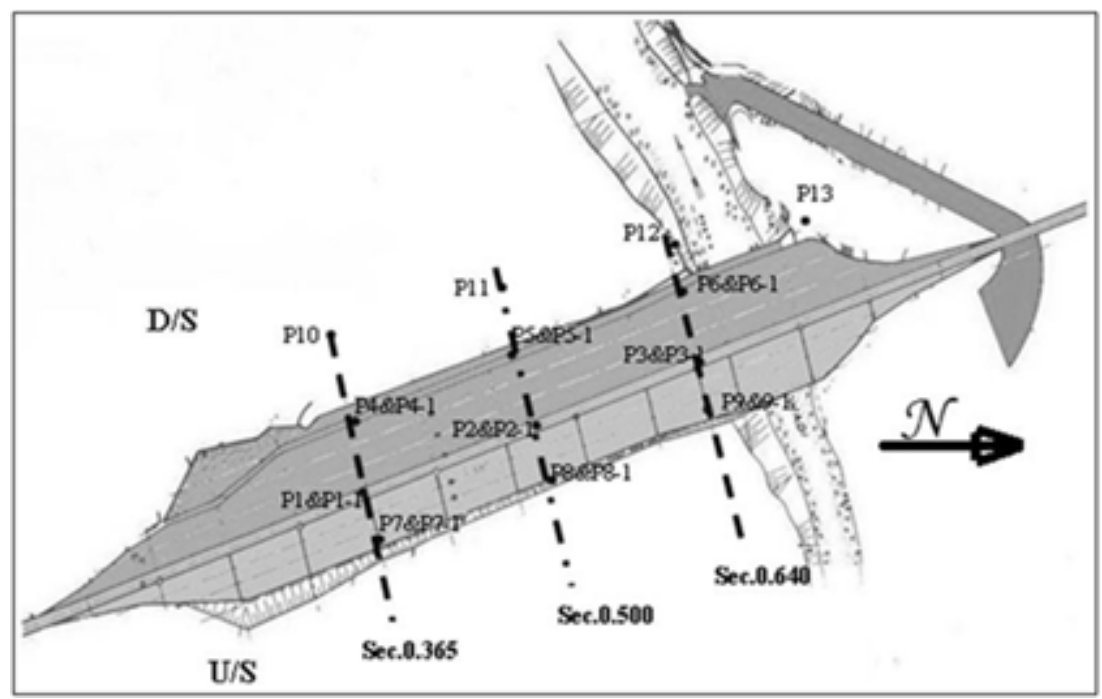

Figure (13): A plan of the piezometers along the dam.

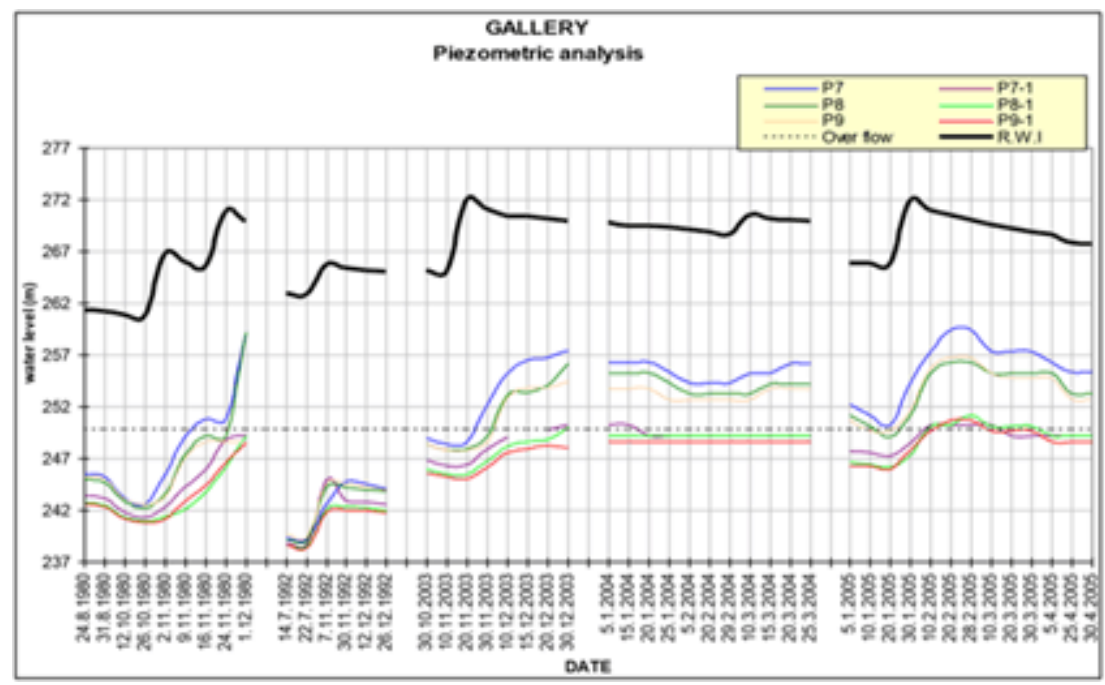

Figure (14): Variation of variation of gallery Piezometers

\section{Discussion}

Ground penetrating radar (GPR) information from profile $\operatorname{Pr}_{1}$ located about $200 \mathrm{~m}$ away from dam toe showed the critical zone beyond $40 \mathrm{~m}$ depth in alluvium formation. Probably these zones are the route for water losses through the surrounding ground and recharge to ground water. This can be justified by the water loss in the reservoir storage estimated at 4.257 mcmbetween the $1^{\text {st }}$ of November and $31^{\text {st }}$ of December 1979 as stated in the annual report for the dam operation in 1979 [4].

Profiles $\mathrm{Pr}_{2}, \mathrm{Pr}_{3}$, and $\mathrm{Pr}_{4}$ are profiles approximately parallel to dam toe. Figure (12) shows different in the three colors referring to critical zones below surface of the reservoir lake and also the widths of critical zones along the profiles. Profiles $\operatorname{Pr}_{5}, \operatorname{Pr}_{6}$ are profiles extending to previous profiles as of figure (7) as well as the position of gradient is into the dam foundation. These profiles are connected by piping or passes. Profile $\operatorname{Pr}_{7}$ located adjacent to dam toe indicated that the critical zone is not deep within the range of 10 to $15 \mathrm{~m}$ (Eel. 248.5), and is located near the concrete piles which are below the base of gallery.

Profiles $\operatorname{Pr}_{8}, \operatorname{Pr}_{9}$ show critical zones located in a limestone and sandstone formations. Probably there are correlations between critical areas for this information and critical areas for $\left(\operatorname{Pr}_{10}\right.$ and $\left.\operatorname{Pr}_{11}\right)$. GPR results are indicating connection between both areas. Profile $\operatorname{Pr}_{12}$ showed two critical zones at depth 5 to $10 \mathrm{~m}$. They are located close to the dam toe in the downstream. These areas are usually saturated zone. Therefore, they are significant to the relation between reservoir variation and water level in the downstream.

Piezometric levels provided additional information about the seepage problem through and around the dam .As shown in figure (14) the maximum reservoir water level reached was $272 \mathrm{~m}$. When reservoir reached over $265 \mathrm{~m}$ the water level in piezometers reaches $249.65 \mathrm{~m}$ (a.s.1). The first affected by reservoir water level rise was P7, then P9 followed by P8. The lag time of this influence ranged from 13 days to 15 days. Piezometers (P7-1, P9-1 and P8-1) have 
been influencing after previous process. Overall, from previous results the water was flowing through the dam base. The distribution of piezometer network has allowed the establishment of three cross section namely; section $(0.365)$, section $(0.500)$ and ection $(0.640)$ shown in figure (14).

Section $(0.365)$ is located at the left bank consists of group of piezometers (P7, P71, P1, P1-1, P4, P4-1 and P10) but $(\mathrm{P} 1-1)$ is not working. Piezometric levels fluctuations shown in figure (15) indicate: There are good correlation between reservoir head and piezometers head. P7 is more influenced with reservoir water level. Water paths are parallel to the valley

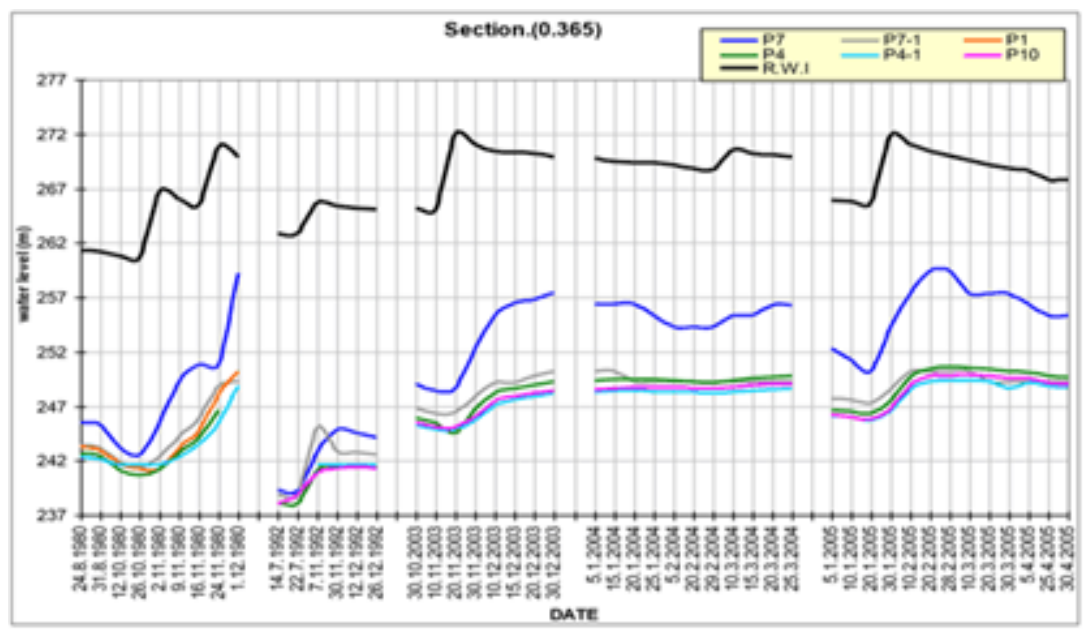

Figure (15): Variation of the piezometers level in section 0.365 and lake level with time

Section (0.500) is located at the central part of the dam, consists of Piezometer P8, P8-1, P2, P2-1, P5, P5-1 and P11. Figure (16) shows the following: P8 is rising to over flow at 249.65 ( $\mathrm{m}$ a.s.l) depending on water reservoir rising level over 265 ( $\mathrm{m}$ a.s.l) while P8-1 is showing the same behavior while reservoir water level is reaching the elevation of $270 \mathrm{~m}$ (a.s.1.)

Section (0.640) is located at the right bank of the dam; consists of P9, P9-1, P3, P3-1, P6, P6-1 and P12. The fluctuation showing piezometric response following the peak of the filling (Figure 17) . All piezometers are indicated that the response occurred with reservoir filling. After filling up on 2003 and 2005 the water elevation in $\mathrm{P} 12$ is very close to the elevation of the valley bed at 247.5 ( $\mathrm{m}$ a.s.l). On that date seepage losses appeared in the valley bed.

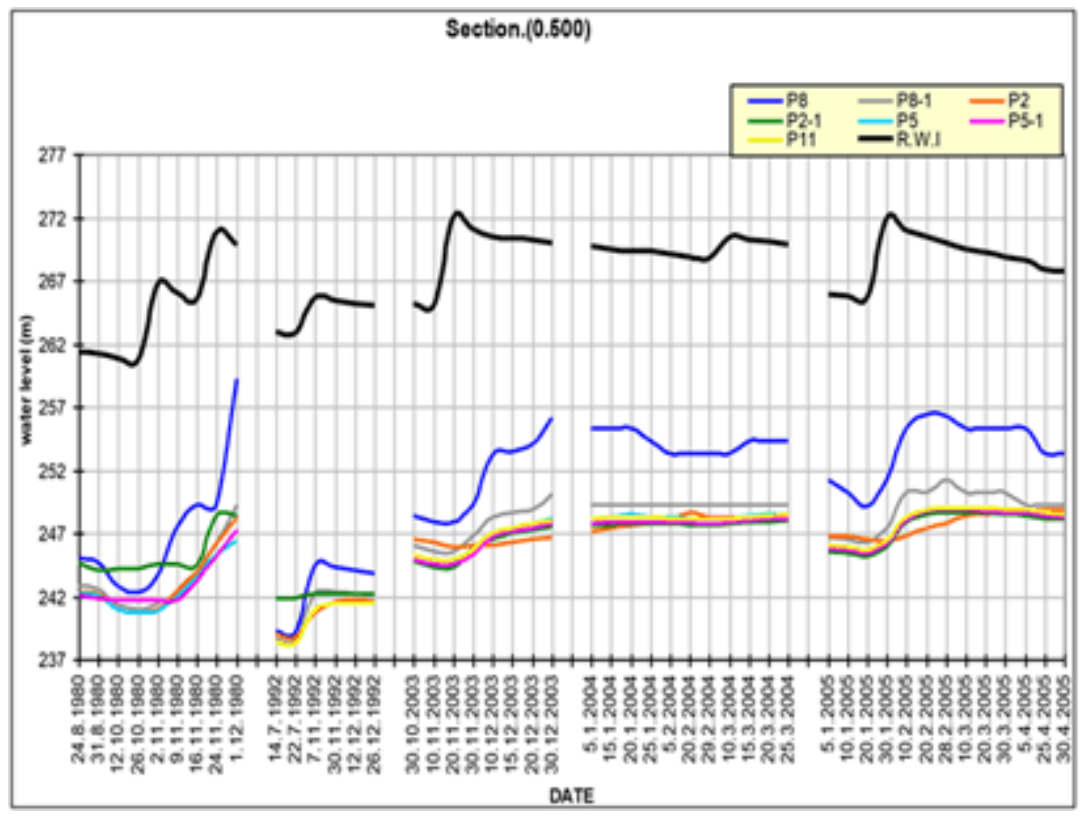

Figure (16): Variation of the piezometers level in section 0.500 and lake level with time 


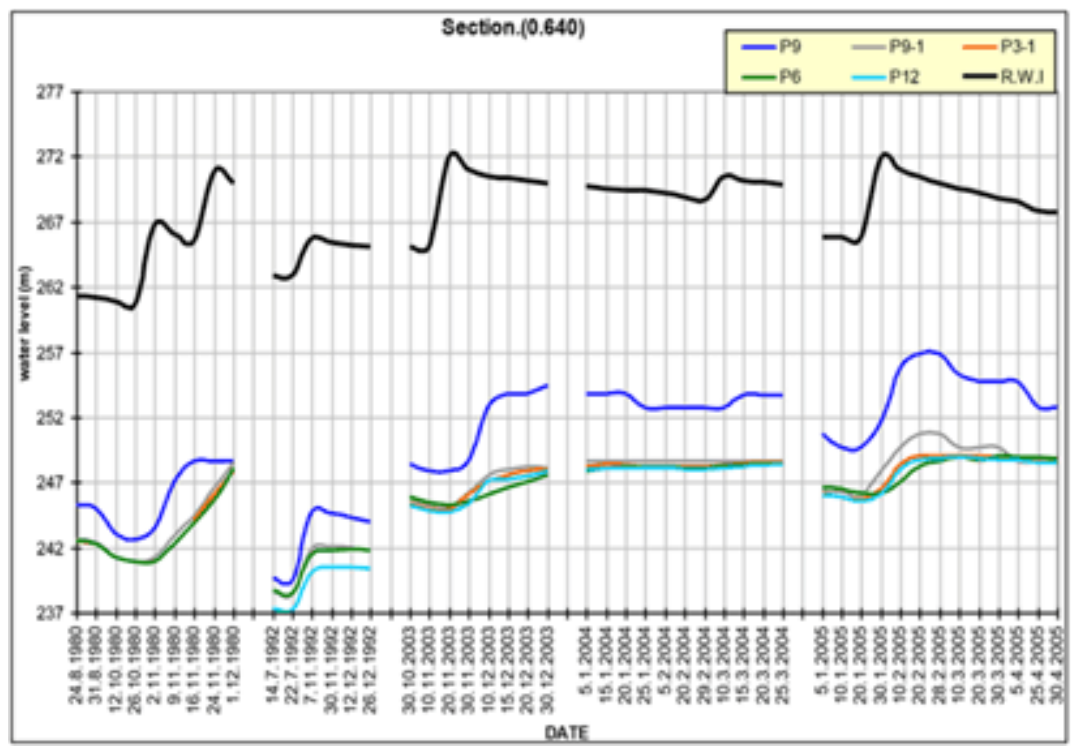

Figure (17): Variation of the piezometers level in section 0.640 and lake level with time

The temperature variation in the piezometers groundwater observations at two periods February ,17 and 21,2008 shown in tables ( 2 and 3 ) were evaluated .The temperatures indicate the most direct connection with cold water from reservoir. The piezometers in central part showed lowest temperature around 16 to $17 \mathrm{C}^{0}$, while piezometers at downstream showed highest temperature comparing to the others. There are correlation and response of the temperature changes in piezometers water and the reservoir water

Table (2): Temperature of reservoir and piezometers water on February 172008.

\begin{tabular}{lllllllll}
\hline Location & Res. & P7 & P7-1 & P4 & P4-1 & P10 & P8 & P8-1 \\
\hline Temp. C & 13 & 17 & 16.5 & 16 & 16.5 & 17.5 & 16.5 & 17 \\
Location & P5-1 & P11 & P9 & P9-1 & P6 & P6-1 & P12 \\
Temp. C & 16 & 17 & 17.5 & 18 & 16.5 & 16.5 & 19 & 19.5 \\
\hline
\end{tabular}

Table (3): Temperature of reservoir and piezometers water on February 21, 2008.

\begin{tabular}{lllllllll}
\hline Location & Res. & P7 & P7-1 & P4 & P4-1 & P10 & P8 & P8-1 \\
\hline Temp. C & 12.5 & 17.5 & 17 & 16 & 16.5 & 17.5 & 17 & 17 \\
Location & P5-1 & P11 & P9 & P9-1 & P6 & P6-1 & P12 \\
Temp. C & 16.5 & 17.5 & 17.5 & 18 & 17 & 17 & 18.5 \\
\hline
\end{tabular}

Flow net analysis was made using the measurements of piezometric levels taken on 20/11/2003 were used to plot water level in contour map. On that day the highest water level in the reservoir was recorded AT $272.02 \mathrm{~m}$ (a.s.l). The distribution of ground water levels beneath the dam shown in figure (18) indicates the following: Hydraulic gradients are low to be consistent with medium permeable. The seepage is flowing in different points through grouting curtains. The contour lines indicate response of variation piezometers and reservoir level. The direction of flow shows two distinctive directions, toward the right.

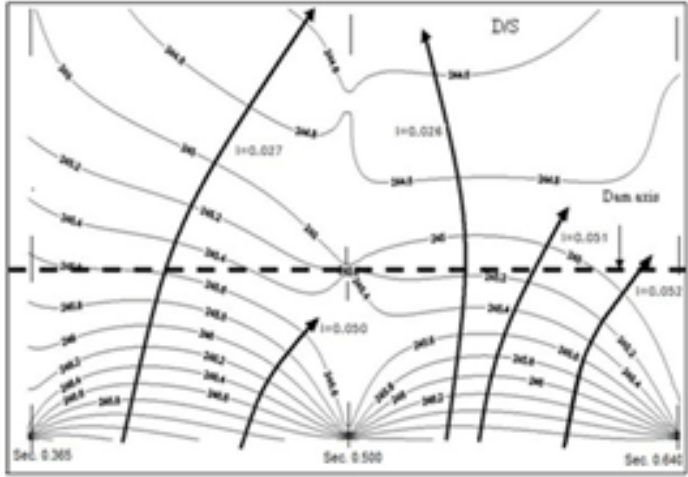

Figure (18): Contour map of the underground water on 20/11/2003 
Network of piezometers in dam site have detected seepage water. Piezometres levels are difficult to identify where major seepage take place. This is because only the gradients of the piezometric surface can be observed directly, and the same gradient occurs for a low flow in low permeability ground as for high flow in high permeability ground. However, figure (18) shows the level of water seepage and gradient of contours. The gradients are low, therefore permeability in foundation is medium and the direction of flow is as mentioned previously.

The volume seepage through the dam was estimated through the flow net technique, which consists of flow lines and equipotential lines. The flow net as shown in figure (19) performed using information from piezometers P9, P9-1, P3, P3-1, P6, P6-1 and P12, and the event of maximum water level in reservoir occurred on March 20,2003.The seepage quantity can be estimated by the following formula:

$$
\mathrm{q} . \mathrm{k} \frac{\mathrm{Nf}}{\mathrm{Nd}}
$$

Where: $q=$ Total quantity of unit flow

$k=$ Permeability coefficient.

$N f$. Number of potential drops.

Nd. Number of flow channel.

$\mathrm{H}=$ Total head losses (h1-h2).

The piezometer section 0.640 appears to have greatest permeability probability along zone foundation so it has been used for calculating seepage. The formation, of the foundation zone in the central of the dam, consist of concrete pile row extend below an elevation of $230 \mathrm{~m}$ then grouting curtain connected between piles and bedrock at an elevation $220 \mathrm{~m}$ as shown in figure (19). The seepage zones under the central dam consist of alluvium layer and grouting curtain. The permeability coefficient $(\mathrm{k})$ for existed grouting curtain was assigned to $\left(5 \times 10^{-8} \mathrm{~m} / \mathrm{s}\right)$ and used as design permeability coefficient.The reservoir water level was $(271.15 \mathrm{~m} \mathrm{asl})$, and (249 $\mathrm{m}$ asl) for the piezometer level (P12) at downstream.

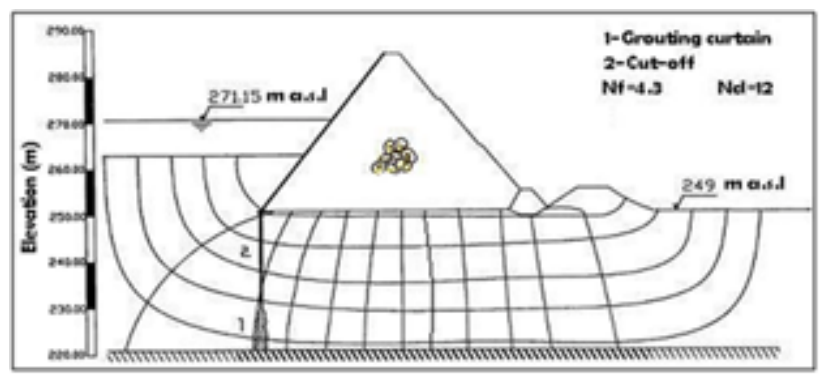

Figure (19): Flow net model for peizometer section 0.640

The reservoir was gradually decreasing $(2 \mathrm{~cm}$ per day). Also the water seepage in bed seep beyond the dam was decrease until water seepage stopped, when water level in reservoir reaching to (266 $\mathrm{m}$ asl). The measurement of sediment bed in the reservoir is at an elevation $(262 \mathrm{~m}$ asl $)$ therefore, this elevation is considered as a new reading for reservoir bed. Quantity of the seepage flow $(q)$ in wadi bed beyond the dam considered to be about $0.25 \mathrm{l} / \mathrm{s}$.

From above graph:

$\mathrm{Nf}=4.3$, and $\mathrm{Nd}=12$

$\mathrm{H}=\mathrm{h}_{1}-\mathrm{h}_{2}$

$\mathrm{h}_{1}=$ Waterdepth in reservoir (Water elevation - Sediment elevation)

$\mathrm{h}_{2}=$ Water depth at downstream

$\mathrm{h}_{1}=271.15-262=9.15 \mathrm{~m}$

$\mathrm{h}_{2=} 0.25 \mathrm{~m}$

$\mathrm{H}=9.15-0.25=8.9 \mathrm{~m}$.

Taking grouting permeability $\mathrm{k}(\mathrm{gr})=5 \times 10^{-8} \mathrm{~m} / \mathrm{s}$

Flow quantity along section (0.640), using formula (1) is $\mathrm{q}=1.6 \times 10^{-7} \mathrm{~m}^{3} / \mathrm{s}$ per meter. Hence capacity of seepage along the dam axis $\mathrm{Q}=\mathrm{q} \times \mathrm{L}$ where $(\mathrm{L}=500 \mathrm{~m})$, then $\mathrm{Q}$ $=7.97 \times 10^{-5} \mathrm{~m}^{3} / \mathrm{s}=0.081 / \mathrm{s}=6889 \mathrm{l} /$ day.

Comparing the amount of total seepage capacity (Q) through the foundation determined during March 20,2003 flood $(0.08 \mathrm{l} / \mathrm{s})$ with the amount of total seepage capacity assigned during design $(0.012 \mathrm{l} / \mathrm{s})$, it seems that the calculated amount is greater than the figure estimated during the design. This phenomena may leads to conclude that the amount of seepage was increased due to development in permeability of the critical zones.

Distribution of water losses under, around and across the dam was delineated using the GPR and Piezometric information. From GPR investigation several critical zones were located. Those zones were found to coincide with the flow path determined from piezometric levels behavior. Both approaches allow delineating water losses path in the reservoir of Megenin dam shown in Figure (20).

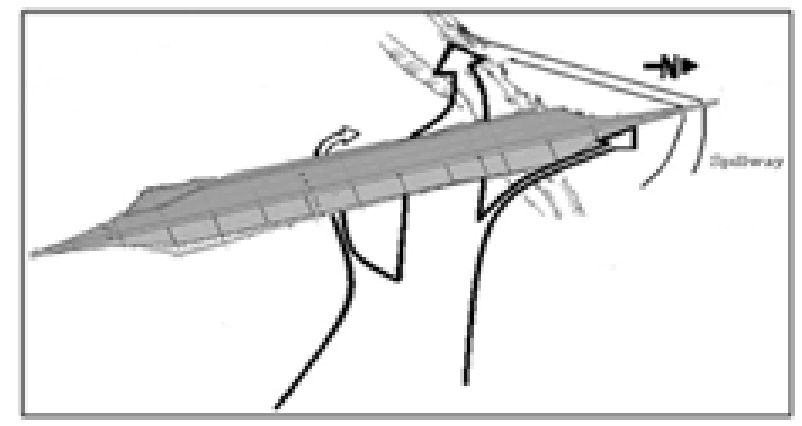

Figure (20): Distribution of water reservoir losses

According to the available results the following assumption can be proposed concerning water losses from the reservoir: part of the seepage amount is recharged to ground water from the area surrounding the reservoir within the level at 271 (asl).

The mount of water passes through upstream concrete facing joints and under central base of the dam. Major amount of water seems to seep through formation of right bank. Minor amount of seepage passes through base dam in left bank. These amounts are sharing seepage water beyond dam body at downstream. 


\section{Conclusions}

The application of the GPR survey determined the direction and distribution of critical zones which ease the flow of water while the flow net model estimated the amount of flow below the dam as the results can impact the safety of dam. The flow net analysis during 2003 flood indicates the amount of seepage more than the figure given during the design time. This increment in the amount of seepage looks very high and must be considered with caution, since the duration of critical seepage occur only when the level of water in the reservoir rises above $270 \mathrm{~m}$ asl. However, the results obtained from GPR survey indicate that the critical zones are very near from grout curtain and dam's foundation. So the impact of seepage problem needs continuous monitoring as its critical zone keeps expanding and following different routes.

GPR survey detected the anomalous zone regarding; the existence of critical zones under the surface of reservoir bed ,under the dam body and under the spillway. Three directions of water flow indicated along the extension of critical zones and coincide with the location where seepage showed its existence downstream. The temperature variation in dam embankment revealed the seepage flow position

It is recommended to establish surface water gauging to monitor any sudden increase in the seepage discharge in bed wadi at downstream .Maintain the upstream concrete facing joints. Design and implement a monitoring program to monitor water levels in the observation wells as well as monitoring seepage water beyond the dam, in order to observe if soil particles removal occur. In case of alert condition occurred additional raw of grouting curtain must be constructed along the full length of the dam to protect dam foundation from flowing water and retaining water upstream of the dam body.

\section{References}

[1] Army Corps of Engineers, 2007. "The Wolf Creek Dam Seepage Problem" http//www.1rn.usace.army.mil/WolfCreek/seepage.htm

[2] HRI, Regional training, 2003 "Engineering of Dams and Seepage through Earth and Rock Fill Dams, Cairo-Egypt

[3] GWA, Dams Department-Libya "Megenin Booklets, 2007"

[4] Hidroprojekat Consulting Engineering, 1974-1983 "Monthly Reports for Megenin Dam "Beograd - Yugoslavia.

[5] Mala Company, 2005. "GPR Systems" Sweden, http:// www. Mala.Com

[6] Sherared J.L, 1972. " Specialty Conference on Performance of Earth and Earth- Supported Structure" ASCE.

[7] Solava \& Delatte, 2003. "Teton Dam Failure Case Study" 3rd ASCE Forensics Congress, October 19-21, 2003, Santiago, California.

[8] Stocky Swiss Engineering, June 2004 "Wadi Megenin DamLeakage Studies"

[9] T. Yokoyama, 2003. "A Temperature Analysis of Ground Water Flow System inUpper of the Ashigara Plain" Hot Spring Research Institute of 